When he becomes drunk there is no kind hand to hide his weakness or take him home; he is "found drunk" in the street, arrested, and fined or imprisoned. The fines, be they small or great, are rarely forthcoming; consequently, this treatment soon resolves itself into prison, prison, prison, and again prison. The degenerating and hardening effect of gaol life upon habitual drunkards is fully realized, and the advanced defective state of those inebriates who have been sent to reformatories is undoubtedly due largely to the preceding years of alternating drunkenness and prison. Regarded as a remedy for habitual drunkenness, especially when we remember its mental basis, oft-repeated confinement in prison is indefensible and inhuman. That auch a course should ever have become established is evidence of oldtime Ignorance concerning the neurotic aspect of the condition ; that, in face of all evidence of uselessnees, it still persists, is inexplicable.

The Inebriates Act of 1898 was meant to substitute reformatory treatment for prison procedure, but as it stands it only partially serves its purpose. It is quite right, and in full accord with English methods, that every possible safeguard should exlst to prevent the misuse or careless administration of any Act which enables interference with personal liberty. But in designing such safeguards there is always the possibility of hedging procedure to such an extent as to render proper working almost impossible; or if not imposslble, then of such limited scope as to materially affect its value. After nearly eight years' experience of the Act in question, those who are in a position to judge will tell you that some such result has been attained. It is still easy to send habitual drunkards to prison, and exceedingly difficult to send them to reformatories; until the reverse is the case full advantage will never be obtained from an Act which might otherwise prove of inestimable value.

\section{WORK FOR THE SOcIETY FOR THE StUdY OF} INEBRIATY.

It is for a society such as this to seriously consider whether or: not some means cannot be devised to remedy this unsatisfactory state of affairs, and, if found, pressed home with a view to early adoption of generally improved methods. It is quite useless to wait and hope for uni vereal abstinence to provide $a$ remedy; the evil must $b$ attacked in a common-sense manner, as a mental probleme under existing conditions in the presence of alcohol, Only three and a half millions out of Eomething like forty. or more in the kingdom are teetotalers; we cannot afford to wait until the remainder are converted, or until alcohol is banished from the world. Total abstinence societies have been established for something like a hundred years, with the result that moderate people have become more moderate, and many moderate persons have become teetotalers. An excellent result for excellent work, because abstinence and strict moderation is conducive to good physique, national health, and national prosperity. It is also probable that some mentally unstable persons have been saved by abstinence from becoming drunkards. But bas the actual number of habitual drunkards decreased as the result of all this temperance energy? I think not. The handred years is, of course, a matter of history so far as I am concerned, and I have insufficient confidence in the value of statistics to pass an opinion concerning that length of time; but I can say something about the last twenty-five years, which I have spent entirely amongst drunkards and drunkenness. I do not belleve, during that period, that habitual drunkenness has decreased, and so far as women are concerned, I am convinced that it has materially increased. The reason seems to me plain enough: whilst temperance workers have succeeded in inducing the moderately strong-minded healthy man to exercise restraint and avoid alcohol, they have been unable to do much towards obtaining the rame result in regard to the very persons who need it most, those who cannot realize the fact, or carry out the remedy. Whilst temperance societies have been preaching teetotalism to persons capable of listening to and benefiting from the appeal, thousands of persons are drinking daily in the slums of London, and making others drunkards by force of example and precept. These rersons are not in the least affected by orthodox temperance efforts; they continue to propagate drunkenness, and thereby nullify the good results of temperance energy. Their children, born of defective parents, and educated by their surroundings, grow up without a chance of decent life, and constitute the reserve from which the strength of our present army of habituals is maintained. Truly we have neglected in the past, and are still neglecting, the main source of drunkard supp]y - the drunkard himself; cripple that, and we should soon see some good result from our work.

Tbere is much to be done, and much this Society could do to help in the direction of improvement; indeed, I know of no body better corstituted for the work. What we want is full consideration of the possibllity of stronger legislation, enabling earlier control and treatment for inebriates, irrespective of their personal opinion as to its necessity. It is also desirable to consider whether, as a first step, the principle of guardianship, already adopted in other countries, could not be made applicable to the needs of England; and whether, in the event of failure to produce good result by guardianship, power should exist for compulsory committal to institution care on certificate and evidence. It is also necessary to have a well-discussed opinion as to whether, after years of control, and after every possible effort at reform has been tried, continued drunkenness and evldent mental defect should not warrant an indeterminate sentence, with occasional licence to be at large; and whether some arrangement could not be arrived at to render impossible the future manufacture of habitually drunken prison recidivists. These are all matters upon which the evidence and opinion of this Society would be valuable, and subjects which seem to me to be of the utmost importance. I am not prepared to say that a satisfactory solution of any one of them is yet within the range of practical politics: but unless some distinct effort is made, I am satisfied that none ever will be.

\section{Intradurtary Adùress} \section{THE CHOICE OF A MEDICAL CAREER,}

MEDICAL ETHICS :AND ETIQUETTE.

Dehiveri d at the Meath Bospital and County Doblin INFIRMARY.

BY JAMES CRAIG, M.D.Dub.,

REGISTRAR, ROYAL COLLEGE OF PHYSTCIANS OF IRELAND : PHYSICIAN TO THE MEATH HOSPITAL AND COUNTY DUBLIN INFIRMARY.

[A FTER some preliminary observations. and after discussing some of the openings for young medical men in England and in the pablic services, Dr. Craig continued as follows:]

The Irish Poor-law Mrdical Skrvice.

What prospects, however, lie before the majority who have a wish to remain in their own country? In the chief towns it is here and there possible for a good cless practitioner to make a living wage by private practice alone; but in.most cases, even in the larger towns, it will be found that the men who are able to live in even comparative comfort are those who have the emoluments attached to a Poor-law appointment to supplement the amount that is to be gained from private practice. There is small chance, therefore, for a practitioner to make a comfortable livelihood in Ireland outside of the teaching centres unless he is able to secure a Poor-law appointment either as visiting surgeon to a union infirmary or as medical officer of a dispensary district.

I cannot in all honesty recommend these positions to those of you who may bave such a career in view, for apart from the evils associated with the efforts to secure these positions, to which I will allude later on, the service suffers from the disabilities attached to meagre pay, uncertain holidays, and doubtful pensions.

Abler pens than mine have been used with perennial fertility to expose the disabilities under which the officers of the Poor-law Medical Service suffer. It is not my purpose here to denounce this service with the virulence which my pen could command, for with all its shortcomings it is possible for a man to lead a happy life in 
ministering to the sufferings of the poor, although he mas find it bard at times to pay his weekly bills. Up to the present, in the matters of salary, holidays, and superannuation, the service has not been one that offered a bright prospect for an ambitious youth. But of recent years some improvements have been taking place, mainly owing to a combined agitation on the part of the majority of the medical profession, and indeed everything polnts to a further continuance of the policy which bas led to a recognition by some of the Boards of Guardians of the justice of the claims of their medical officers.

It is to be feared, however, that the increases in salaries that have already been adopted have been, for the most part, in the districts where the pinch of poverty was least felt among the medical officers; and this inequality is a crying shame, but the medical profession are awaiting some definite action on the part of the Local Government Board authorities to compel the unions which up to the present have either rejected or failed to consider proposals to improve the position of their medical officers to do their duty in the matter.

I regret to say. that not the least formidable obstacle to Poor-law medical reform has arisen from the selfish and unsportsmanlike conduct of members of the medical profession themselves. It has been mostly among the younger men that this disloyalty has occurred. Let me cite an example: A medical vacancy occurred in a nnion in the North of Ireland. The salary offered was quite inadequate, and the neighbouring medical men in loyalty to a decision of the Irish Medica Association, unanimously agreed to abstain from com peting for the appointment. The guardians would have been compelled ultimately to offer an increased salary, which would have been in some measure commensurate with the amount of work required from the medical officer; but this was not to be, for a young gentleman from the gouth of Irelond, equipped with the degrees of the Uni versity of Dublin, and who, in other circumstances, would have stood no chance whatsoever of being chosen, off $-r e d$ himeelf for election, and, in spite of remonstrances urged from many sources, persisted in his candidature, and was in the end elected. I am not in a position to state whether this gentleman is yet tired of doing work at a remuneration which the Irish Medical Association and men of experience and knowledge of the Jocality had decided to be entirely insufficient; but at all events $I$ know of no excuse that could justify the lack of esprit $d e$ corps shown by him. We may, however, assume that inexperience and ignorance were accountable for this act of eelfish folly, which the medical profession was bound to condemn. But it is just such acts of folly that help to retard the long-needed reforms in the Poor-law Medical Service.

Apart altogether from the questions of salary, holldays and superannuation, one of the gravest objections to this service is the methods which bave to be adopted by candidates in order to cecure an appointment by the votes of the members of the Boards of Guardians. It is very rarely indeed that the question of merit arises. Influence, religion, politics-anything, in short, rather than professional attainments-may secure the support of the electorate. Far be it from me to suggest that men of the highest distinction are not to be found in the Poor-law Medical Service, for such $: 2$ suggestion would be entirely at variance with facts; but that does not in the least minimize the highly objectionable methods that obtain in the securing of these appointments.

I have to admit that objections have been urged against the establishment of a State or National Medical Service as suggested in the recent Report of the Viceregal Commission, but any such reasons that could be adduced ag ainst such a service are small in comparison with the evils that at present exist, and have made the service notorious.

For my own part, I have no hesitation in saying that the entrance to the service should be gained by competitive examination. I say this in spite of the fact that examinations may not be in all cases the highest test of a candidate's ability or fitness for a post, still the adoption of such a principle would give merit the place it deserves in the qualifications necessary for such important positions, and it would at once put an end to the humiliating experiences which candidates at present undergo in canvassing for these appointments. But, far beyond every other consideration, it would make for a more efficient service in the interest of the poor people who are to be treated by the medical cfficers, particularly so if, as should be the case, the scale of ealaries were fixed on a more liberal basis, so that the best class of men turned out from the various medical schools in the country might be encouraged to compete for the appointments.

I believe the statement to be incontrovertible that the establishment of a National Medical Eervice, which would be entered by competitive examination, and in which the medical officers would receive an adequate wage for their services, would make for higher efficlency in the treatment of the poor.

Let us stop for a moment to consider the manner in which the suggestion of the Viceregal Commission for a National Medical Service was received by the medical profession. At what was prokably the largest meeting of medical men ever gathered together in Ireland for the consideration of a specific point, it was decided last autumn by the members of the Irish Medical Association that such a service was highly desirable, the majority in favour of the proposal being at least 10 to 1 .

After a prolonged discuseion in the State Medicine Section of the Royal Academy of Medicine in Ireland, the proposal to establish a national medical cervice was, I believe, unanimously adopted. Further, the Council of the great British Medical Association also approved the scheme on the recommendation of some of its Irish Branches. These expressions of approval of the suggested service, emanating as they did from all sections of the medical profession in Ireland, cannot well be ignored.

The strongest argument that can be adduced against its adoption is that the local bodies, which at present are responsible for raising the money to pay a portion of the salaries of the Poor-law medical officers, would be deprived of the patronage which they now possess in elpcting the candidates for whom they have a predilection.

I frankly acknowledge that this is an objection, and I also admit that to increase the burden on the ratepayers so as to secure more adequate salaries for the members of the service would in many unions be quite impossible. But even these difficulties are not insurerable, and many solutions to them have been already offered. I am unwilling, at this stage, to prejudice in any way the possible inception of the scheme by putting forward $\mathrm{my}$ personal views as to the methods by which it might be made generally acceptable, for I hold a very strong opinion that, acting on the precedent of the Land Conference, the best way to secure a solution of this problem of a National Medical Service would be to get together a round table conference, at which the various interests involved would be reprezented by capable conciliatory men, who would produce a scheme acceptable to the Government and to the interested parties.

I venture to express a confident hope that this as well as many other of the most excellent suggestions put forward by the Viceregal Commission may be given effect to at no distant date. At any rate, a medlcal service in connexion with the treatment of the poor, if instituted on the lines brosdly laid down by the Commission, would command the support of the great majority of the medical profession in Ireland, and would probably put an end to many of the grievances under which the Poor-law medical officers have suffered for many years, and I have no doubt whatsoever but that it would tend to place at the service of the poor, as well as of the paying class in this country, many men of high ability who under present conditions are driven to seek their fortunes in other lands.

Medical Ethics and Etiquette.

This is a side of medical education which receives too little attention, elther from the professors in the medical schools or from the teachers in the hospitals, with the result that young men are allowed to go forth into practice without any knowledge of the pitfalls that await them in their dealings with the other members of the profession and the public.

It has been said that we require no other principle to guide us in our professional conduct than to follow the apostolic teaching of doing nnto others as we would that others should do unto ns. I have no reason to dispale this advice, which is altogether excellent, but, like many 
of the minor commandments, it is much too general in its application to meet many of the questionable points of profes sional conduct that arise in the everyday practice of our profession.

Medical ethics are the rules or principles that should govern our professional conduct. Medical etiquette is the ceremonial to be observed in our relations with one another and with the public. The public have a mistaken notion that medical etiquette consists of some rules unintelligible to them which the medical profession has imposed on its members in order to safeguard their own selfish interests, but which are detrimental alike to the welfare and the pockets of the general public. This is by no means the case, as these rules have been formulated quite as much in the interest of the patient as for the benefit of the members of the medical profession. If these rules at times appear to be faulty, it is generally due to a false interpretation of them.

Permit me, however, first of all, to point out to you a few of the matters that are regarded as unethical in professional conduct, and then I shall say something later on concerning etiquette. You will scarcely have been given time to add to your probably meagre wardrobe the silk hat and frock coat which, with a diploma, go to the making of a professional man, until you will be besieged with requests from the manufacturers of patent medicines and patent foods to give laudatory testimonials of their pro ducts for subsequent publication. All such appeals must be persistently ignored if you desire to run on ethical lines. As time goes on you will be filled with a burning desire to see your names in the daily papors as the authors of marvellous cures, or the performers of some wonderful operations. Whatever valuable discoverles you make are to be used for the advancement of knowledge in your profession, and may only be communicated to the medical societies or medical journals, where your results can be examined and intelligently criticized.

You must be no participator in any public laudation of your own professional achievements. The respect of your professional brethren is a subtle sentiment, won only by slow degrees, but extremely easily lost, and once damaged seldom if ever regained. To win this respect it is necessarg for you to play an honourable part in the game of life, and one of the points upon which the opinion of the profession is most sensitive, and most readily turned in a practitioner's disfavour, is the semblance on his part of any coquetting with the bewitching siren of advertisement. You must endeavour not to obtain practice by any unworthy means-no success, no notoriety is worth the loss of the respect of your brethren in the profession.

Another pitfall which the unwary practitioner must diligently avoid is the giving of prof $\epsilon$ ssional asslstance to unqualified persons-particularly unqualified dentists. It is not permissible for a practitioner to give his professional services to any society or combination of individuals, unless the entire sum of money paid by the members for the purpose of securing medical attendance for themselves and their families finds its way into the coffers of the practitioner.

I have already alluded to the depravity of underselling. particularly where a principle is involved, and the instance $I$ have related should require no further elaboration.

It is not desirable for a practitioner to erect a notice board outside his residence on which is set forth the small value which he places upon his medical skill. It may be that he estimates his services at a shilling or even at half a crown a visit, but it is unbecoming to tell as much to the passer-by.

A leaning towards any form of quackery is certain to place the practitioner immediately without the pale of decent medical society, and where it is openly practised leads at once to ostracism and removal of the practi tloner's name from the Register of the General Medical Council.

Although I have not by any means exhausted the ethical rales which help to regulate professional conduct, I must now pass on to the subject of medical etiquette. First of all it may, perhaps, clear the air of any misapprehension if I state quite clearly that no individual member of the public is to be regarded as the absolute property of any medical man. The public must be permitted to have a free choice in the selpction of a medical attendant, but whether they are wise to be chopping and changing their attendant is quite another matter. During the progress of any specific illness if a patient sees fit to change his medical adviser, the medical profession expect that an intlmation will be glven by the patient to the practitioner in attendance that his services are no longer required. This is to prevent possible misunderstandings from arising between the medical men, and to ensure that the patient will not be subjected to the advice and treatment of different medical advisers at one and the same time.

In a case of emergency where a practitioner is called upon to see a patient in the absence of the regular medical attendant, the former should communicate the $f$ sct to the latter at the earliest possible moment, and he should not remaln in attendance after the regular attendant is available ; further, where for any reason practitioner has been placed in charge of patients by brother practitioner, he must exercise the most unceasing care neither to undermine the faith of the patients in their own absent attendant, nor afterwards himself undertake the treatment of such patients.

In the matter of consultations it is a practitioner's duty to accept with alacrity the earliest hint from a patient that a second oplnion on his case would be gratifgiog either to himself or to his friende; but there are certain conditions in which it is imperative upon him to urge the necessity for further advice and assistance without waiting for a request from the patient or his friends. The Ethical Committee of the British Medical Association have formulated these cases as follows:

(a) When a question arises of the propriety of performing an operation or adopting some course of treatment which may be dangerous to life or permanently injure the condition of the patient, especially if the condition which it is sought to rolieve by this treatment be not itself dangerous to life.

(b) When a question arises of destruction of a fetus or unborn child in the interest of the mother.

(c) When the practitioner in attendance is definitely in doubt elther as to the diagnosis or as to the treat ment to be followed, and when delay in arriving at a decision might be fraught with serious consequences to the patient.

(d) When there is evidence of serious doubt in the mind of the patient or his friends as to the correctness of a diagnosis or of the treatment pursued.

(e) When the attendant has reason to suspect :

(i) Performance of any illegal operation.

(ii) Administration of poison.

(iii) Commission of any other criminal offence.

In regard to the choice of a consultant, it is generally expedient to follow the wish of the patient or his relatives; but if the case is one which demands special knowledge, it is the practltioner's duty to endeavour to secure the services of the consultant from whom he expects to derive the greatest assistance. The practitioner in attendance arranges for the consultation, and punctuality on the part of both advisers is so necessary that it is not incumbent on either to wait beyond a reasonable time. Failing punctuality, the consultant may see the patient in the absence of the other. The regular attendant enters the patient's room first and leaves it last, and the opinion arrived at after consultation should be communicated to the patient in the presence of the regular attendant. If a difference of opinion exists between the two medical practitioners it is most desirable that it should be communicated to the patient or his friends, so that further advice may be obtained in the Interest of the patient. The regular attendant should inform the patient or his friends as to the amount of fee to be paid to the consultant. Where a personal consultation is impossible the medical attendant should write a letter of information and introduction to the consultant, who in turn communicates his opinion and suggestions as to treatment to the medical attendant.

There are two most essential rules which it is the duty of the consultant to observe in the strictest manoer. In the first place, he should exercise the most scrupulous care to avoid disturbing the confidence of the patient in his ordinary medical attendant; and in the second place he should not supersede the practitioner through whom he has received an introduction to the patient. This latter rule seems to be somewhat at variance with the general principle which was previously laid down-that the public must not be regarded as the private property of any individual practitioner; but, again, this rule has been 
formulated for the advantage of the public, so as to lessen any possible contingencies that would tend to detract from the freedom of consultations.

In conclusion, let me say that there is one point upon which it is almost impossible to give advice, and that ishow far a knowledge of a patient's actual condition should be communicated to himself by his medical attendant. In many instances it is right to take a patient entirely into your confidence. In some cases, however, it would be most injurious for his future well-being that his actual physlcal condition should be explained to him; but this much I can say, that where a practitioner has no doubt in his own mind as to the serious nature of an illness he shoald be perfectly candid with the friends of the patient, and thereby obviate any reflections that might possibly be cast upon him at a later period.

\section{THE CALMETTE SERUM REACTION IN OPHTHALMOLOGY.}

By SYDNEY STEPHENSON, M.B., C.M.

IT would be a truism to say that our ordinary methods of clinical examination not infrequently leave us in doubt as to whether a patient is or is not affected with tuberculosis, dormant or otherwise. This is especially apt to be the case when tuberculous foci exist in the bronchial or mesenteric glands. The injection of tuberculin is undoubtedly of service in the recognition of these conditions. Its use however, implies confinement to bed or to hospital ward, the careful taking at frequent intervals of the patient's temperature, systematic records of weight, and, last but not least, the methodical determination of the opsonic index. These requirements stand in the way of the everyday use of tuberculin as a diagnostic agent.

In June last Dr. A. Calmette ${ }^{1}$ announced a new method of diagnosing tubercle of almost incredible simplicity. His plan was to place a drop of a 1 per cent. watery solution of dried tuberculin in the eye of the patient. In the case of healthy subjects the result of the application was nil. On the other band, the tuberculous subject showed a local reaction, now widely known as the "ophthalmoreaction of Calmetle." From the third bour onwards the eye to which the tuberculin had been applied became reddened, and in the course of several hours showed all the appearances of a more or less pronounced attack of acute muco-purulent inflammation of the conjunctiva. The maximum reaction was geen within six or seven hours after the application of the tuberculin. All traces of inflammation had disappeared within two or three days. The plan is free from danger, and causes the patient scarcely any discomfort.

Calmette's results have been confirmed by Prouff, Grasset and Rimkaud, ${ }^{3}$ and other French and Swiss observers. Indeed, it can scarcely be doubted that the genius of Dr. Calmette has placed in our hands a most simple, trustworthy, and efficient means of recognizing the existence of tubercle in any part of a patient's body.

Now, apart from lesions of the eye recognized by all competent observers as tuberculous, there are several others-especially chronic irido cyclitis, scleritis, and some forms of choroiditis-of which the tuberculous origin is as loudly proclaimed by one school as it is decried by another. The preponderating part anquestionably played by syphilis in the production of many of these affections has, perhaps, tended to render some of us a little blind to the influence of other causes, prominent among which, as I believe, stands tuberculosis. How often do we meet with disseminated choroiditis, indistinguisbable by the ophthalmoscope from the form due to syphilis, in patients in whom there is no evidence whatever of a specific taint, acquired or inherited. I feel tolerably confident that the systematic employment of the ophthalmo-reaction will show that no small number of such non-syphilitic cases are in reality due to tuberculosis.

Calmette's serum has already been used in eye work by Painblan, who obtained positive results in a couple of cases of tuberculosis of the conjunctiva. Brunetière ${ }^{8}$ had negative results in 3 cases thought possibly to be of tuberculous origin-kerato.iritis, interstitial keratitis, and exudative choroiditis. Aubaret and Lafon ${ }^{6}$ employed the serum in 18 eje cases, including intraocular tuberculosis, phlyctenular conjunctivitis, and keratitis, episcleritis, Interstitial keratitis, lacrymal affectlons, and, lastly, optic papillitis. Brunetière. ${ }^{7}$ in the course of a second communication, while reaffirming the diagnostic value of the serum, regretted that it could not be applied to every ảoubtful case.

My personal experiences with the Calmette serum are far from complete, but up to the present time I have applied it to the eyes of upwards of thirty patients, all of whom were suffering from some disease or affection of the eye. The more important casss may be briefly described as follows:

1. Phlyctenular (Eczematous) Conjunctivitis and Keratitis.The tuberculous origin of these common affections of the eye has been suspected for years, and the view is widely held at the present day that they are caused by a tuberculous toxin circulating in the blood stream. The Calmette serum was applied to the ejes of six children, all of whom had been affected with long-standing and relapsing ulceration of the cornes. Only two of the patients manifested tuberculous lesions elsewhere. The ophthalmo-reaction, however, was obtained in every instance. On the other hand, the result was negative once in a case of recent phlyctenular keratitis. It is to be noted that Aubaret and Lafon (loco citato) elicited the ophthalmo-reaction in 4 healed cases of phlyctenular disease.

2. Choroiditis.-The serum has been applied in 3 cases of choroiditis in young women, Iree, as far as could be ascertained, from evidences of syphilis, acquired or inherited. Two of the patlents were single, and the third married. The choroiditis was bilateral in 2 and unilateral in 1 case. The choroidal lesions were of long standing. In Case No. 1 the gross disseminated "choroiditis presented no ophthalmoscopic features whereby it could be differentiated from a syphilitic process. In Case No. 2 the changes affected almost exclusively the central region of the fundus. Case No. 3 showed in the central region of one fundus a map-like area of choroiditis, and while under observation a secnnd area of disease made its appearance below the optic disc. Each eye was myopic to the extent of $3.5 \mathrm{D}$. In each of these three patients the ophthalmoreaction was obtained, although in none had a tuberculous focus been found by clinical examination.

3. Interstitial Keratitis.-Of the 8 cases tested, 5 manifested obvious stigmata of inherited syphilis, and it is significant in them that the ophthalmo-reaction was not elicited. On the contrary, in the remaining 3 cases positive results were forthcoming in all.

4. Episcleritis.-One case of eplscleritis was tested, with positive reaction to the serum. The patient, a wolnan aged 19 years, showed two massive episcleritic patches, one above and the other below the right cornea. The fundi were normal. A suggestlon of tuberculosis was given, by the fact that the cervical, inguinal, and axilary groups of glands were somewhat enlarged. Two other cases in women, aged 50 and 28 years respectively, yielded no reaction to tuberculin.

5. Tuhercle of Iris.-A female, aged 12 years, was admitte $j$ to the North-Eastern Hospitsl for Children on August 2nd last suffering from a disabling affection of the left eye of nearly six months' duration. The anterior chamber of the left eye was almost filled with solid-looking, yellowlsh-greg exudation, so that the pupil could be recognized with difficulty. The eye was somewhat reddesed, tension was. slightly minus, and sight was equal on]y to counting the outspread fingers when held close to the child's face. No clinical signs either of tubercle or of syphills. The state of the eje was so characteristic, however, that I did not hesitate to diagnose 1 uberculosis of the iris and ciliary body, of the form described in systematic treatises as "iritis scrofulosa" or "conglomerate tubercle." For that matter, the tuberculous nature of the process was attested by the general reaction that on two occasions followed the injection of $\gamma^{+} \delta 5 \mathrm{mg}$. of tuberculin T.R. It was confirmed later by the action of the Calmette serum. On September 22nd, a drop of the liquid in question was instilled into the child's unaffected eze by Dr. R. A. Chisolm resldent medical officer to the hospital. A well-marked reaction came on in nine hours, and persisted for twenty hours.

6. Tubercle of Cornea.-A girl, aged 12 years, was seen by me on May 29th, 1907, with the history that her right eye 